\title{
Double Pylorus: Report of a Case With Endoscopic Follow- Up and Review of the Literature
}

\author{
Fotios Fousekis ${ }^{\mathrm{a}}$, Panagiota Aggeli ${ }^{\mathrm{a}}$, Panagiotis Kotsaftis ${ }^{\mathrm{b}}$, \\ George Pappas-Gogos ${ }^{\mathrm{c}}$
}

\begin{abstract}
Double pylorus is a rare endoscopic finding that has been reported in $0.001 \%$ to $0.4 \%$ of upper gastrointestinal endoscopies and can be either congenital or acquired. Acquired double pylorus is usually an uncommon complication of peptic ulcer that erodes and creates a fistula between the duodenal bulb and the prepyloric antrum. We describe a case of a 67-year-old man who experienced mild epigastric pain and dyspepsia over the last 6 months. The patient periodically took nonsteroidal anti-inflammatory drugs (NSAIDs) due to joint pain. Esophagogastroduodenoscopy revealed gastritis and a double pylorus. An accessory channel connected the lesser curvature of the prepyloric antrum to the duodenal bulb and the endoscope was able to be passed through both of the ducts. The Helicobacter pylori quick test proved positive. Two years later, a follow-up endoscopy showed that fistula fused with normal pylorus and there was a single large opening.
\end{abstract}

Keywords: Double pylorus; Gastric ulcer; Helicobacter pylori; Follow-up

\section{Introduction}

Double pylorus or duplication of the pylorus is a very unusual endoscopic finding that has been reported only in $0.001 \%$ to $0.4 \%$ of upper gastrointestinal endoscopies and consists of two channels connecting the prepyloric antrum to the duodenal bulb [1]. The etiology can be either congenital or acquired. Acquired double pylorus appears more often and, in most cases, can be a complication of a chronic gastric ulcer that penetrates, erodes and creates a fistula between the duodenal bulb and the prepyloric ulcer or can very rarely be the result of a penetrating gastric cancer or the consequence of a duodenal bulb ulcer

Manuscript submitted January 7, 2018, accepted February 8, 2018

${ }^{a}$ Department of Gastroenterology and Endoscopy Unit, Filiates General Hospital, Filiates, Greece

bepartment of Internal Medicine, Filiates General Hospital, Filiates, Greece 'Department of Surgery, Filiates General Hospital, Filiates, Greece

${ }^{\mathrm{d} C}$ Corresponding Author: Panagiota Aggeli, Eleftheriou and Kavafi, Filiates 46100, Igoumenitsa, Greece. Email: abournetas@yahoo.gr

doi: https://doi.org/10.14740/gr960w
[2].The location of the second duct is more frequently present in the lesser curvature of the prepyloric antrum and epidemiologically, double pylorus occurs twice as often in males when compared to females [3]. In our case, during the esophagogastroduodenoscopy of a conventional case, we demonstrated an acquired double pylorus, probably due to gastric ulcer.

\section{Case Report}

The patient was a 67-year-old man, who arrived at the emergency department and referred with chronic epigastric pain and dyspepsia over the last 6 months and felt weakness. He suffered from diabetes mellitus type 2 and high blood pressure and took medications for both diseases. Currently, he reported that he periodically took nonsteroidal anti-inflammatory drugs (NSAIDs) for arthralgia during the last year, without taking inhibitor of gastric acid and he denied having black or bloody stools. Physical examination revealed only mild upper abdominal tenderness and the blood tests showed microcytic anemia with hemoglobin $10.1 \mathrm{~g} / \mathrm{L}$ and iron deficiency with ferritin 13 $\mathrm{ng} / \mathrm{mL}$ and iron $27 \mu \mathrm{g} / \mathrm{dL}$. He underwent an esophagogastroduodenoscopy and colonoscopy as an outpatient due to gastrointestinal symptoms and microcytic anemia. The colonoscopy was normal, while the esophagogastroduodenoscopy revealed a normal esophagus, gastritis with erosions, a double pylorus and a normal duodenum. Specifically, an accessory channel connected the lesser curvature of the prepyloric antrum to the duodenal bulb and the endoscope was able to easily pass via both of the pyloric channels (Fig. 1).

Furthermore, the Helicobacter pylori quick test proved positive, while histological examinations of gastric antrum and corpus showed chronic active gastritis in both of them and H\&E stain revealed a large amount of Helicobacter pylori bacteria. Finally, the patient was treated successfully with concomitant therapy for the eradication of Helicobacter pylori (metronidazole $500 \mathrm{mg}$, amoxicillin 1g, clarithromycin 500 $\mathrm{mg}$ and lansoprazole $30 \mathrm{mg}$, twice a day for 10 days). The eradication was verified via a stool antigen test for Helicobacter pylori, 1 month after treatment. In addition, he took iron supplements, continues to take proton pump inhibitor once a day and has limited the use of NSAIDs. The symptoms were eliminated after a few weeks from the inception of therapy and the hemoglobin was normal after 5 months. Two years later, a follow-up endoscopy revealed that the bridge between the two channels was disappeared and there was only single large 


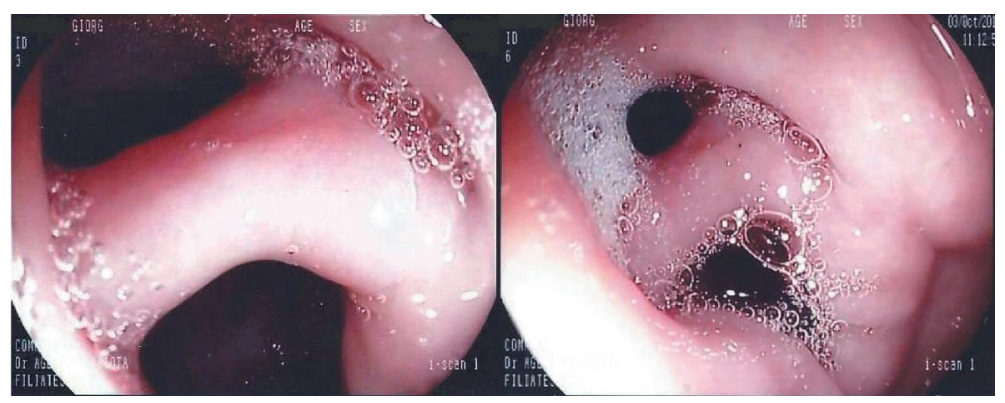

Figure 1. Endoscopic view from the antrum demonstrates double pylorus. The two openings are separated by a bridge from tissue.

opening (Fig. 2). The stomach, duodenum and esophagus were normal. In addition, biopsies were taken from the gastric antrum and body, which showed chronic inactive gastritis, while $\mathrm{H} \& \mathrm{E}$ stain proved to be negative for Helicobacter pylori.

\section{Discussion}

The development of congenital double pylorus occurs during early stages of embryonic development and its diagnosis requires normal histology between the two openings, which shows normal mucosa and muscularis mucosa layer and lack of peptic ulcer [4]. It has been reported with other congenital abnormalities, such as pancreas divisum [5] or heterotopic pancreatic tissue [6], while in a case report; congenital double pylorus was described with achalasia [7]. Diagnosis of congenital double pylorus is made accidentally in patients who undergo upper gastrointestinal endoscopy. Moreover, congenital double pylorus does not require any therapy or extensive investigation.

Conversely, an acquired double pylorus almost always appears symptomatic and patients can suffer from chronic upper abdominal pain, vomiting, dyspepsia or present upper gastrointestinal bleeding. Additionally, patients often have a long

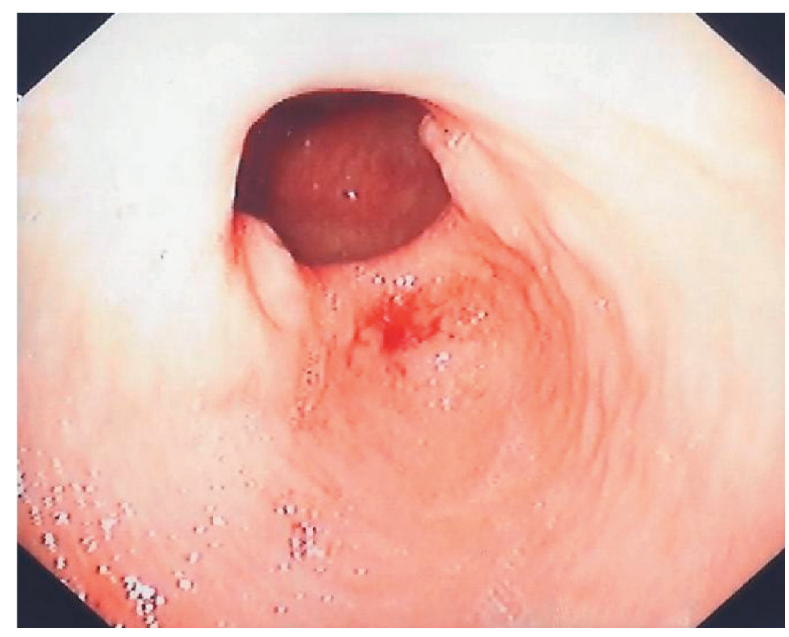

Figure 2. Gastroduodenal fistula has fused with normal pylorus and there is a single large opening. The remnant tissue of the bridge of the opposite sides can be easily noted. history of treatment with NSAIDs or corticosteroid. In our case, the patient had chronic mild epigastric pain, anemia and periodically took NSAIDs. Endoscopists often demonstrate an ulcer over the accessory pyloric channel. Also, it is essential that double pylorus be discriminated from gastric diverticulum [8]. In patients with double pylorus, an investigation for Helicobacter pylori is necessary, because as has been reported, a correlation exists between the development of a double pylorus and Helicobacter pylori and patients who have been infected with Helicobacter pylori should be treated. What is more, medications for the reduction of peptic acid should be taken and ulcerogenic medications, such as NSAID and corticosteroid, should be avoided [1].

Seldom can double pylorus cause gastric outlet obstruction. Endoscopic treatment, using biliary sphincterotome for dividing the bridge tissue, is feasible to be performed. Furthermore, surgical intervention should be considered when endoscopic treatment has failed or a peptic ulcer persists despite the maximum medical therapy due to contribution of double pylorus to bile acid reflux or in the case of free perforation [9, $10]$.

Double pylorus has been associated with other underlying comorbidities, such as diabetes mellitus, chronic obstructive pulmonary disease, rheumatic arthritis, cirrhosis, Behcet's disease, systemic lupus erythematosus and chronic renal failure $[11,12]$. It is considered that patients with these disorders often take ulcerogenic medications, such as NSAIDs and steroids, or the disorders themselves may contribute to poor healing of peptic ulcer and lead to the development of peripyloric, a gastroduodenal fistula [13]. One case report described double pylorus in a patient with an adrenal adenoma and the authors believe that the formation of double pylorus in this case resulted from recurrent peptic ulcer, which was induced by the hypersecretion of endogenous corticosteroids accompanying adrenal adenoma [14]. Regarding this case, the patient suffered from diabetes mellitus type 2 , which has been correlated with the development of peptic ulcer and delayed, poor gastric ulcer healing [15].

Concerning the natural history of acquired double pylorus, according to a retrospective follow-up study in patients who were treated with an $\mathrm{H} 2$ receptor antagonist or proton pump inhibitor after the diagnosis of acquired double pylorus, the fistula remained open in the majority of patients (64\%), fused with normal pylorus in $27 \%$ of patients and closed only in $9 \%$ of cases [3]. In our patient, the fistula fused with normal py- 
Table 1. Characteristics of Acquired Double Pylorus

\begin{tabular}{ll}
\hline $\begin{array}{l}\text { Incidence } \\
\text { Clinical presentation }\end{array}$ & $\begin{array}{l}\text { Chronic upper abdominal pain, dyspepsia, upper gastrointestinal bleeding, vomiting } \\
\text { Causes }\end{array}$ \\
Risk factors & $\begin{array}{l}\text { Glcerogenic medications, Helicobacter pylori, adrenal adenoma, diabetes mellitus, chronic obstructive disease, } \\
\text { chronic renal failure, Behcet's disease }\end{array}$ \\
Differential diagnosis & $\begin{array}{l}\text { Congenital double pylorus, gastric diverticulum } \\
\text { Complications }\end{array}$ \\
Treatment & Gastric outlet obstruction, persistence gastric ulcer \\
\hline
\end{tabular}

lorus 2 years after diagnosis (Table 1).

In addition, it is worth noting that endoscopists should be aware of the double pylorus so as to avoid complication during side view endoscopy, such as endoscopy retrograde cholangiopancreatography (ERCP) and longitudinal endoscopic ultrasound (EUS) [16].

\section{Conclusions}

Double pylorus is an uncommon endoscopic finding and has been correlated with congenital abnormalities, Helicobacter pylori, comorbidities and frequent receipt of ulcerogenic medications. In acquired double pylorus, treatment with anti-ulcer medications should be performed. Moreover, endoscopists should be aware of the double pylorus in order to avoid complications during side view endoscopy, such as ERCP and longitudinal EUS.

\section{Conflict of Interest}

The authors declare that there is no conflict of interest regarding the publication of this article.

\section{References}

1. Lei JJ, Zhou L, Liu Q, Xu CF. Acquired double pylorus: Clinical and endoscopic characteristics and fouryear follow-up observations. World J Gastroenterol. 2016;22(6):2153-2158.

2. Matsuyama E, Nagashima R, Watanabe S, Takahashi T. Endoscopic hemostasis for hemorrhage from gastric cancer complicated by double-channel pylorus. Gastrointest Endosc. 2001;53(6):679-680.

3. Hu TH, Tsai TL, Hsu CC, Lu SN, Hsiao M, Changchien CS. Clinical characteristics of double pylorus. Gastrointest Endosc. 2001;54(4):464-470.
4. Naidoo R, Singh B. Congenital double pylorus. Case Rep Gastrointest Med. 2012;2012:537697.

5. Sisman G. Concomitant pancreas divisum and double pylorus: a case report. JOP. 2014;15(6):632.

6. Wolters VM, Nikkels PG, Van Der Zee DC, Kramer PP, De Schryver JE, Reijnen IG, Houwen RH. A gastric diverticulum containing pancreatic tissue and presenting as congenital double pylorus: case report and review of the literature. J Pediatr Gastroenterol Nutr. 2001;33(1):8991.

7. Gupta A, Hollander D. Duplication of the pylorus found concomitantly with achalasia: congenital or peptic etiology? Am J Dig Dis. 1977;22(9):829-830.

8. Bhattacharya K. Gastric diverticulum - 'Double pylorus appearance'. J Minim Access Surg. 2005;1(1):39.

9. Goh BK, Tan HK. Double pylorus. Am J Surg. 2006;191(4):515-516.

10. Graham SM, Lin F, Flowers JL. Symptomatic doublechannel pylorus. Successful treatment with a biliary sphincterotome. Surg Endosc. 1994;8(7):792-793.

11. Fattahi MR, Homayoon K, Hamidpour L. Double pylorus in a cirrhotic patient: a case report and review of the literature. Middle East J Dig Dis. 2012;4(2):130-132.

12. Hatemi I, Hatemi G, Erzin YZ, Celik AF. Double pylorus in a patient with Behcet's syndrome. Clin Exp Rheumatol. 2015;33(6 Suppl 94):S138-140.

13. Safatle-Ribeiro AV, Ribeiro Junior U, Habr-Gama A, Gama-Rodrigues JJ. Double pylorus: case report and review of the literature. Rev Hosp Clin Fac Med Sao Paulo. 1999;54(4):131-134.

14. Yousuf M, Kameya S, Noda A, Watanabe T. A case of double pylorus accompanied by adrenal adenoma. Am J Gastroenterol. 1989;84(2):173-175.

15. Peng YL, Leu HB, Luo JC, Huang CC, Hou MC, Lin HC, Lee FY. Diabetes is an independent risk factor for peptic ulcer bleeding: a nationwide population-based cohort study. J Gastroenterol Hepatol. 2013;28(8):1295-1299.

16. Sauer B, Staritz M. [The double pylorus - a rare endoscopic finding]. Dtsch Med Wochenschr. 2012;137(8):368-370. 